\title{
Conflicting intra-departmental views on the importance of simulation in general surgery
}

\author{
K. Brandon Lang, ${ }^{a}, *$ Todd F. Hoover, ${ }^{b}$ Marie Hunsinger ${ }^{c}$ and Mohsen Shabahang ${ }^{c}$ \\ ${ }^{a}$ Sociology, Social Work and Criminal Justice, Bloomsburg University, 400 East Second Street, Bloomsburg, PA 17815, USA; ${ }^{b}$ Early \\ Childhood and Adolescent Education, Bloomsburg University, 400 East Second Street, Bloomsburg, PA 17815, USA; ${ }^{c}$ General \\ Surgery, Geisinger Medical Center, 100 North Academy Avenue, Danville, PA 17822, USA \\ ${ }^{*}$ Corresponding author at: Sociology, Social Work and Criminal Justice, Bloomsburg University, 400 East Second Street, \\ Bloomsburg, PA 17815, USA. Email: klang@bloomu.edu
}

Date accepted for publication: 4 February 2020

\section{Abstract}

Background: Although the technology has improved over the years, simulation is not used as widely in general surgery resident education as it is in other medical specialties. The aim of this study was to examine what general surgery residents and general surgeons like and do not like about simulation-based education. Methods: Unstructured focus groups were conducted at a moderate-sized general surgery residency program involving three groups of residents (interns, mid-levels, and chiefs) and two groups of attending physicians $(n=27)$. In each of the groups, respondents were asked to articulate their views concerning the importance of simulation training. A qualitative analysis of the data was performed. Results: The attending physicians perceive the value of the simulation lab to be less effective than the operating room in terms of teaching surgical skills. In general, they see being part of an actual surgery to be more beneficial than working in a simulated environment. Conversely, the residents perceive simulation labs to be hands-on and educational, and as a low-stress environment to develop their surgical skills. Conclusions: This study demonstrates that faculty and residents have different views concerning the importance of surgical simulation. It also suggests that residents are in a bind. Many of them seek to be more involved in actual surgeries but feel that active learning in the simulation lab is more beneficial than passive learning in the operating room.

Keywords: surgical simulation; residents; general surgery

\section{Introduction}

For decades, simulators have been widely used in a variety of educational contexts to help train people to maneuver airplanes, operate heavy machinery, and improve their welding skills, among many other things. Across many fields, simulation technology provides an increasingly realistic training and testing experience that has become fully integrated into the respective training curricula of dozens of demanding and prestigious professions. Even though medical simulation has been around for decades, it has not been as widely used in general surgery as in other specialty areas. This is due to many factors, including time constraints, a perceived dearth of realistic simulation devices, and the widely held assumption that observing a real surgery is a better educational opportunity than working on a dummy. The purpose of this study was to compare the views of residents and attending physicians concerning the role of surgical simulation in the specialty training of general surgery.

\section{Literature review}

Even though most studies on the effectiveness of medical simulation are relatively recent, the medical simulation literature is expansive. Moreover, it clearly establishes that when used in conjunction with other forms of training, simulation can be very effective in improving the technical skills of medical students and residents, building their confidence and establishing a sense of teamwork with others. According to Agha and Fowler, "Research is increasingly showing that simulation improves learning and has the potential to meet the needs of trainees and satisfy the 
regulatory needs of the profession and society." Studies also note that simulators are becoming more common, ${ }^{2}$ more authentic, ${ }^{3,4}$ and more integrated into residency programs. ${ }^{5}$

There are numerous studies that point to the benefits of surgical simulation labs. Okuda et al. ${ }^{6}$ conducted a review of 113 studies and found that surgical simulation was, by and large, beneficial for residents. For example, they found that simulation training is associated with improvement in procedural performance in the operating room (OR), better adherence to the advanced cardiac life support protocol, improvements in medical knowledge, increased comfort in procedures, and improvements in performance in retested simulated scenarios. ${ }^{6}$ They also found that simulation has been shown to be a reliable tool to assess learners and teach topics such as teamwork and communication. ${ }^{6}$ Many more recent studies support Okuda et al.'s findings that residents benefit from simulation training. ${ }^{7-11}$

In a meta-study examining all the research concerning the effectiveness of simulation-based education (SBE) up to 2013, Cook et al. ${ }^{12}$ found that going back to 1973 , research supports that simulation is an effective educational technique. Cook et al. ${ }^{12}$ identify 432 studies that have been published that identify the favorable outcomes of SBE compared with no simulation-based interventions at all. In a similar study conducted by McGaghie et al., ${ }^{13}$ the authors examined the effects of simulation training published in 109 articles published in a wide range of medical journals between 1969 and 2003 and drew similar conclusions. ${ }^{13}$ They conclude that simulation-based medical education is an effective intervention but also note that simulation compliments rather than duplicates any education that involves real patients in what they refer to as genuine settings. ${ }^{13}$

As mentioned above, simulation involves more than improving a resident's surgical skills. Thus, simulation training has the potential to help people learn from their mistakes, correct them, and even prevent them from happening in the future. ${ }^{14}$ According to Ziv, ${ }^{14}$ "The basic assumption underlying SBME (Simulation Based Medical Education) is that increased practice in learning from mistakes and in error management in a simulated environment will reduce occurrences of errors in real life and will provide professionals with the correct attitude and skills to cope competently with those mistakes that could not be prevented."

Although the literature concerning medical simulation is generally positive, it is important to recognize that several studies have established some concerns. For example, Davies et al. ${ }^{15}$ found that most of the literature focuses on laparoscopic, endovascular, and endoscopic surgical simulation and few studies examine open surgical simulation.
Evgeniou and Loizou ${ }^{16}$ also make clear that simulation training can only be effective once it is successfully integrated into a surgical curriculum and aligned with clinical practice. In other words, the benefits of simulation are maximized when a balance is struck between the simulated environment and the clinical one. According to Chang et al., ${ }^{17}$ the residents in their study benefited from simulation training, but they did not think that it served as a good substitute for actual operative experience. They also found that participation in simulation training should be mandatory because few residents engaged in it when simulation was deemed voluntary. Finally, Kunkler ${ }^{18}$ notes that the sooner that simulation training is integrated into a resident's weekly curriculum, the better the results. Thus, it is not as beneficial when introduced later in a resident's training.

\section{Methods}

This research was conducted in autumn 2015. After obtaining institutional review board approval from the hospital, focus groups were conducted with residents and attending physicians in the general surgery department at a large teaching hospital. All the focus group transcriptions and questionnaires were anonymous, and it was made clear to respondents that they could suspend their involvement at any time.

The focus groups were divided according to the experience level of the respondents (Table 1). There were three groups of residents, including interns, mid-years and chiefs, and two groups of attending physicians (pre-duty-hours era and post-duty-hours). Overall, the focus groups included 27 residents and attending physicians. Email messages were sent to all the residents and attending physicians asking them to join these focus groups. The focus groups were held on weekday afternoons and a meal was provided. Focus group attendees were also asked to complete a short questionnaire about their learning styles and the importance of ten learning environments within the hospital (see Appendix 1). Because of schedule conflicts, not everybody was able to participate. Of the 27 focus group members, 19 (70.4\%) were residents.

The focus groups that we conducted were formal (in a work setting) and unstructured. As seasoned qualitative practitioners, we felt comfortable initiating a discussion with the respondents that was organic and conversational. Our goal was to generate a relaxed environment where the discussion was free flowing. We also had material that we sought to cover. We outlined our major research questions to all the groups and asked everyone to tell us a little about 
Table 1. The professional experience of respondents

\begin{tabular}{lll}
\hline Experience level & Number & Percentage \\
\hline Residents $(n=19)$ & & \\
Interns & 6 & 22.2 \\
Mid-years & 9 & 33.3 \\
Chiefs & 4 & 14.8 \\
Attending physicians $(n=8)$ & & \\
Pre-duty hours & 4 & 14.8 \\
Post-duty hours & 4 & 14.8 \\
Total & 27 & 100 \\
\hline
\end{tabular}

themselves. In several of the groups, we asked a series of questions relating to the respondents' dominant learning styles, the appeal of general surgery, the different responsibilities of residents and the ways in which residents are evaluated (Table 2).

Because the focus groups were unstructured, numerous respondents answered questions in a manner that initiated further discussion among the group members. We asked many follow-up questions and followed several conversational threads (Table 3). These threads examined such issues as the degree of social distance between most residents and most interns, the presence of busy work, and the role of efficiency in the OR.

Each of the focus groups lasted about 1 hour. The discussions were recorded, transcribed, coded, and analyzed. The focus group members also completed a short anonymous survey.

\section{Results}

Based on our focus groups and surveys, residents and attending physicians share similar views regarding the importance of rounds and lectures in the surgical development of residents. They see both as being valuable in teaching the residents a range of skills, including surgical techniques, interactions with patients, and time management. Our data show, however, that the residents and attending physicians do not agree on the effectiveness of surgical simulation labs and the role of residents, especially lower-level ones, in the OR.

\section{The simulation lab}

Our focus groups revealed that residents and attending physicians have different views concerning the effectiveness of the surgery simulation labs. In short, the residents feel that the simulation labs are educational opportunities that allow
Table 2. Interview questions posed during several of the focus groups
1. What drew each of you to general surgery?
2. What responsibilities do residents undertake over the course of a typical day?
3. What kind of learner are you?
4. What learning environments (OR, rounds, clinic, etc.) do you think are the most conducive to learning? Which ones are not, in your opinion?
5. How does the evaluation process work for residents?
6. What do you all think about the simulation labs?
7. What do you like most about being in the OR?
8. If there is one thing you could change about the program, what could be changed that might help the program?

Table 3. Conversational threads followed up during individual focus groups

1. How would you characterize the social distance between you
and the attendings? Is it formal? (asked to interns)
2. How does it work socially with you and the interns? Is there a
caste system? (asked to mid-years)
Would you agree that some of what residents do is busy
work? (asked to chiefs)
How does efficiency play out in the OR? Is it fair to say that
some people do the procedure more quickly than others?
(asked to pre-duty-hours attendings)
Is pimping a positive educational tool? (asked to post-duty-
hours attendings)
Is it okay for a resident to say that they don't know the
answer to a question? (asked to post-duty-hours
attendings)
Can you maybe tell us about some of the challenges and
differences between your experiences as a resident and
coming here to be an attending? (asked to post-duty-hours
attendings)

them to learn in a lower stress environment. One resident remarked that, "There is a little of it [simulation lab] now, but I think there should be more. We are surgeons, so we need to learn this. We need a very relaxed atmosphere to make mistakes and learn from that." Our focus group data clearly show that residents enjoy the low-stakes nature of the simulation lab and see it as something that they can really benefit from.

The clear consensus among attending physicians in the focus groups is that simulation labs are not as effective in teaching surgical skills as being in the OR. One attending physician stated that, "I find it silly to leave the real thing to go to simulation, so they make hours like simulation 12 to 1 when you have a real surgery going on." Another noted that, "Simulations are usually basic stuff. Until you are in 
the OR, once you get past that first step, I don't think simulation helps." This is confirmed by our survey data, which show that, based on an 80-hour work week, residents feel that they should engage in roughly 1.5 hours more time in the simulation lab per week than the attending physicians (7.1 hours/week versus 5.4 hours/week) (Table 4).

When asked about how effective they thought simulation labs are, one attending physician stated that it is, "Only so good. Some things you can learn from it, but you have to be in the OR." Another stated, "I have had people who looked at me and said they have to do simulations to pass up scopes on real people, which is absurd. There is a big move right now with the educators' society that we do need to do simulations [and we] shouldn't set a resident loose on a real patient."

Similarly, another attending physician stated, "That [simulation] makes sense, but I think that the thing is in the surgery residency you need to be in the $\mathrm{OR}$ as much as humanly possible. You learn by watching people, not by a video. You gradually learn how to do it in real time. There is a lot of teaching going on, but probably not a lot of learning."

One thing that both the residents and attending physicians seem to agree on, however, is that it is difficult to carve out the time to go to the simulation lab. Moreover, there are not enough simulators for everyone so people have to share, which makes the process more time consuming. One resident also noted that, "There's not enough stuff [equipment] in here. More simulators and having the time to go into the simulation room, even an hour a week would make a big difference." This sentiment was widespread among the residents.

\section{The operating room}

Without question, the OR is an essential training ground for surgical residents. Among other things, it allows residents to put into practice many of the concepts that they learn about in lectures, textbooks, and in the clinic. Meyerson et al. ${ }^{18}$ developed the "autonomy gap" as a concept to explain the lack of resident involvement in many common surgical procedures. Their findings suggest that surgical faculty and residents share similar views concerning resident operative autonomy, but that resident performance does not always meet faculty expectations. ${ }^{19}$ In the words of Meyerson et al., ${ }^{19}$ the "autonomy gap" provides "more evidence for concerns about the preparedness of graduating residents for independent practice."

The main issue for many of the residents in this study is that they feel that they do not have many opportunities to actually hone their craft while in the OR. One resident stated, "I think there were less restrictions in the past. Some people were left alone in the OR and had more autonomy. I'm in my 2nd year and I barely touched someone in the OR." Another stated, "I'm shocked every time someone goes into the OR and he said 4th year had no supervision, so I think the autonomy changed. They had a lot more freedom. We have a lot less autonomy, we always have an attending in scrubs."

It seems that residents crave more autonomy in the OR. They are very eager to not only be in the OR but to be given meaningful responsibilities. One resident noted that,

Table 4. Average responses for the actual and ideal amounts of time that residents spend per week in ten different learning environments

\begin{tabular}{|c|c|c|c|c|c|c|}
\hline & \multicolumn{3}{|c|}{ Actual amount of time (\%) } & \multicolumn{3}{|c|}{ Ideal amount of time (\%) } \\
\hline & Total & Residents & Attendings & Total & Residents & Attendings \\
\hline Operating room & 21.7 & 18.9 & 28.1 & 40.2 & 39.5 & 41.9 \\
\hline Clinic & 14.9 & 15.9 & 12.5 & 10.1 & 9.4 & 11.9 \\
\hline On own & 12.9 & 12.1 & 14.9 & 12.4 & 11.6 & 14.4 \\
\hline Lecture & 11.9 & 11.4 & 13.4 & 8.1 & 8.8 & 6.3 \\
\hline Rounds & 10.5 & 10.3 & 11.3 & 9.2 & 9.6 & 8.1 \\
\hline PowerPoints & 6.9 & 7.8 & 4.8 & 3.0 & 3.3 & 2.5 \\
\hline In groups & 6.2 & 5.8 & 7.0 & 5.2 & 5.8 & 3.8 \\
\hline Simulation & 5.7 & 5.9 & 5.0 & 6.6 & 7.1 & 5.4 \\
\hline Sign-out rounds & 5.7 & 6.2 & 4.4 & 5.5 & 5.4 & 5.9 \\
\hline Other & 3.4 & 4.7 & 0.3 & 0.7 & 1.0 & 0.0 \\
\hline Total & 100 & 100 & 100 & 100 & 100 & 100 \\
\hline
\end{tabular}


"Bottom line, surgeons who let you be more hands-on and make decisions are better."

Interestingly, the attending physicians share a different perspective on this issue. They expressed a number of issues relating to patient safety and time management. Many of the younger attending physicians, for example, made sure to remind us that they were the ones who were ultimately responsible for the well-being of the patients and that there was too much at stake to hand the proverbial "reins" over to a student. It seems that they were not comfortable allowing for the possibility of any sort of mistake to occur. They also made it clear that many of the residents were capable but much slower than themselves. This presented itself as a problem because there is such a high demand for the ORs. Several of the attending physicians noted that it was hard to exercise patience with interns and residents when more surgeries needed to be done.

\section{Discussion}

Clearly, residents and attending physicians share different views concerning the role of simulators and resident responsibilities in the OR. In the grand scheme of things, three-dimensional simulators are fairly new and were not around during the residencies of many established attending physicians. For several reasons, virtually all the attending physicians that we spoke with felt strongly that being in the OR was much more beneficial than working on a simulator. This likely reflects the fact that many of them did not have access to simulation devices during their own residencies and prefer to teach others as they themselves were taught. Many attending physicians had more hands-on training in the OR compared with many of today's residents. In other words, most of them appear to have maintained a level of autonomy that, for several reasons, cannot be attained by today's surgical residents.

With regard to autonomy in the OR, there are two main explanations why attending physicians are very conservative when it comes to asking residents to be involved with surgeries. The first is that this particular hospital is so busy, and because residents are generally slower than attending physicians, this has a negative impact on the hospital's overall operating schedule. Time pressures are also compounded by insurance regulations that favor efficiency. The second explanation is that malpractice lawsuits have become more common, and surgeons, especially younger ones, are reluctant to relinquish that much control and responsibility with so much on the line. Because of the life-and-death nature of surgery, many attending physicians opt to err on the side of caution.
It seems that there is a paradigm shift taking place in surgical training and education. Because change has been slow within the context of surgical training, it makes sense that there is some resistance to the widespread usage of simulators. Not everybody is comfortable with change because it requires people to think and act outside their long-established comfort zones. Although surgical simulation really has the potential to improve the skills and boost the confidence of residents, they are in a bind. This is because they seek the same kind of hands-on training that their preceptors had but often become frustrated when their involvement in the $\mathrm{OR}$ is reduced to a more observational role because of time, insurance, and other constraints. It seems evident that the residents in this study want to be more active in the OR. Because many of them do not feel that they are being offered that opportunity, they would rather actively work on simulators than passively observe surgeries.

This research suggests that there is a clear need for more trainer and trainee awareness concerning the effectiveness of simulation within surgical and other forms of medical education. It is important for educators, for example, to see that simulators have come a long way in recent years and are much more effective than they were even 15 years ago. It is also important for them to recognize that today's surgical learners may have different ways of processing information and levels of self-confidence than they, themselves, had during their training. Residents, on the other hand, may need to become more patient and recognize that the process of going from medical school graduate to practicing specialist is a long one that will present unique challenges of its own. More studies should be conducted on this topic to see if these findings are generalizable across other general surgery programs, in particular, and other residency programs, in general.

\section{Conclusions}

Using data collected in focus groups at a large teaching hospital in central Pennsylvania, this study investigates the extent to which residents and attending physicians agree concerning the benefits of surgical simulators and the role of residents in the OR. Our findings show that residents like the simulation devices because they lower stress and are educational. Conversely, the attending physicians feel that being in the OR is more effective. We also found that residents seek to have more autonomy in the OR. These views are not shared by the attending physicians that we interviewed. Many of the attending physicians in this study appear to still think that being a successful surgeon requires a wide range of skills, such as thinking on one's feet, making adjustments, and working in a team-oriented 
environment that cannot be effectively replicated in a simulated environment.

\section{Conflict of interest}

None declared.

\section{References}

1. Agha RA, Fowler AJ. The role and validity of surgical simulation. Int Surg 2015; 100: 350-357. https://doi.org/10. 9738/INTSURG-D-14-00004.1.

2. Gaba DM. The future vision of simulation in health care. BMJ Qual Saf 2004; 13 (suppl 1): i2-10. https://doi.org/10. 1136/qshc.2004.009878.

3. Montgomery K, Bruyns C, Brown J, Sorkin S, Mazzella F, Thonier G, et al. Spring: a general framework for collaborative, real-time surgical simulation. Stud Health Technol Inform 2002; 85: 296-303. https://doi.org/10.3233/978-160750-929-5-296.

4. Tucker S, Cevidanes LH, Styner M, Kim H, Reyes M, Proffit W, et al. Comparison of actual surgical outcomes and 3-dimensional surgical simulations. J Oral Maxillofac Surg 2010; 68: 2412-2421. https://doi.org/10.1016/j.joms. 2009.09.058.

5. Lane JL, Slavin S, Ziv A. Simulation in medical education: a review. Simul Gaming 2001; 32: 297-314. https://doi.org/10. 1177/104687810103200302.

6. Okuda Y, Bryson EO, DeMaria S, Jacobson L, Quinones J, Shen B, et al. The utility of simulation in medical education: what is the evidence? Mt Sinai J Med 2009; 76: 330-343. https://doi.org/10.1002/msj.20127.

7. Ahmed R, Hughes PG, Friedl FOF, Brito JRC, Frey J, Birmingham LE, et al. A novel simulation technician laboratory design: results of a survey-based study. Cureus 2016; 8: e534. https://doi.org/10.7759/cureus.534.

8. Auerbach M, Stone KP, Patterson MD. The role of simulation in improving patient safety. In: Grant VJ, Cheng A, editors. Comprehensive healthcare simulation: pediatrics. Cham: Springer; 2016; p. 55-66. https://doi.org/10.1007/978-3-31924187-6_5.

9. Kneebone RL. Simulation reframed. Adv Simul 2016; 1: 27. https://doi.org/10.1186/s41077-016-0028-8.

10. Pringle K, Mackey JM, Modi P, Janeway H, Romero T, Meynard F, et al. A short trauma course for physicians in a resource-limited setting: is low-cost simulation effective? Injury 2015; 46: 1796-1800. https://doi.org/10.1016/j.injury. 2015.05.021.

11. Stearns LP, Eales TW, Metts JM, Finnerty EP, Halt KA, Derflinger D. A standardized model for team-based simulation training and assessment of third-year medical students in the acute care setting. Med Sci Educ 2016; 26: 25-29. https://doi.org/10.1007/s40670-015-0195-6.

12. Cook DA, Hatala R, Brydges R, Zendejas B, Szostek JH, Wang AT, et al. Technology-enhanced simulation for health professions education: a systematic review and meta-analysis. JAMA 2011; 306: 978-988. https://doi.org/10.1001/jama.2011. 1234.

13. McGaghie WC, Issenberg SB, Petrusa ER, Scalese RJ. A critical review of simulation-based medical education research: 2003-2009. Med Educ 2010; 44: 50-63. https://doi.org/10. 1111/j.1365-2923.2009.03547.x.

14. Ziv A, Ben-David S, Ziv M. Simulation based medical education: an opportunity to learn from errors. Med Teach 2005; 27: 193-199. https://doi.org/10.1080/01421590500126718.

15. Davies J, Khatib M, Bello F. Open surgical simulation-a review. J Surg Educ 2013; 70: 618-627. https://doi.org/10. 1016/j.jsurg.2013.04.007.

16. Evgeniou E, Loizou P. Simulation-based surgical education. ANZ J Surg 2013; 83: 619-623. https://doi.org/10.1111/j. 1445-2197.2012.06315.x.

17. Chang L, Petros J, Hess DT, Rotondi C, Babineau TJ. Integrating simulation into a surgical residency program. Surg Endosc 2007; 21: 418-421. https://doi.org/10. 1007/s00464-006-9051-5.

18. Kunkler $\mathrm{K}$. The role of medical simulation: an overview. Int J Med Robot 2006; 2: 203-210. https://doi.org/10.1002/rcs.101.

19. Meyerson SL, Teitelbaum EN, George BC, Schuller MC, DaRosa DA, Fryer JP. Defining the autonomy gap: when expectations do not meet reality in the operating room. J Surg Educ 2014; 71: e64-e72. https://doi.org/10.1016/j.jsurg. 2014.05.002.

\section{Appendix 1: The survey instrument used in this study}

\section{Learning styles survey}

My name is Brandon Lang and I am a sociologist at Bloomsburg University. I am conducting IRB-approved research on the different learning styles of medical professionals. Thank-you for taking the time to complete this anonymous questionnaire. Filling out this survey is optional and you can stop at any time.

According to the VARK model, there are four distinct learning styles:

1. visual learners (learn through charts, diagrams, handouts, etc.)

2. aural learners (learn by hearing information in lectures and classes) 
3. reading and writing learners (learn by reading books)

4. kinesthetic learners (learn by touching and doing)

1. Please rank (1-4) the learning styles that best describes how you learn...

Visual

Aural

Reading and writing

Kinesthetic

2. I am..

A resident physician

An attending physician

3. You have 100 marbles to allocate into ten learning environments. How many marbles do you place into each category?

\begin{tabular}{ll|}
\hline & \\
\hline Learning environment & $\begin{array}{l}\text { Number of marbles } \\
\text { Actual }\end{array}$ \\
\hline Clinic & \\
Operating room & \\
Lecture hall & \\
Rounds (am and pm) & \\
Simulation & \\
Sign-out rounds (am and pm) & \\
On your own & \\
In groups & \\
Power points & \\
Other & \\
Total & \\
\hline
\end{tabular}

\section{Results from the survey}

\section{Question 1}

\begin{tabular}{lll|}
\hline & & \\
\hline $\begin{array}{l}\text { Dominant learning style } \\
\text { of respondents }\end{array}$ & Number & Percentage* $^{*}$ \\
Visual & 9 & 33.3 \\
Aural & 2 & 7.4 \\
Reading and writing & 2 & 7.4 \\
Kinesthetic & 1 & 51.8 \\
\hline These scores represent respondents ' answers for their dominant learning style. \\
\hline
\end{tabular}

\section{Question 2}

\begin{tabular}{|lll|}
\hline \multicolumn{3}{|c|}{} \\
\hline Level of experience of respondents & Number & Percentage \\
\hline A resident physician & 19 & 70.4 \\
An attending physician & 8 & 29.6 \\
\hline
\end{tabular}

\section{Question 3}

Results from question 3 are shown in Table 4 . 